\title{
First record of the bee genus Bathanthidium (Bathanthidium s. str.) Mavromoustakis (Hymenoptera: Megachilidae) from Vietnam: Description of a new species and a key to species
}

\author{
Ngat Thi Tran ${ }^{1,2}$, Lam Xuan Truong ${ }^{1,2}$, \\ Toshko Ljubomirov ${ }^{3}$, Lien Thi Phuong Nguyen ${ }^{1,2}$
}

I Graduate University of Science and Technology, Vietnam Academy of Science and Technology, 18 Hoang Quoc Viet Road, Nghia Do, Cau Giay, Hanoi, Vietnam 2 Institute of Ecology and Biological Resources, Vietnam Academy of Science and Technology, 18 Hoang Quoc Viet Road, Nghia Do, Cau Giay, Hanoi, Vietnam 3 Institute of Biodiversity and Ecosystem Research, Bulgarian Academy of Sciences, 1, Tzar Ossvoboditel Boulevard, Sofia 1000, Bulgaria

Corresponding author: Lien Thi Phuong Nguyen (phuonglientit@gmail.com)

Academic editor: Jack Neff | Received 5 September 2021 | Accepted 19 October 2021 | Published 30 December 2021

http://zoobank.org/03725F23-6D56-4E73-AE11-16B8F53E4880

Citation: Tran NT, Truong LX, Ljubomirov T, Nguyen LTP (2021) First record of the bee genus Bathanthidium (Bathanthidium s. str.) Mavromoustakis (Hymenoptera: Megachilidae) from Vietnam: Description of a new species and a key to species. Journal of Hymenoptera Research 88: 51-60. https://doi.org/10.3897/jhr.88.73969

\begin{abstract}
The little-known bee genus Bathanthidium Mavromoustakis, 1953 of the family Megachilidae is reported for the first time from Vietnam. A new species, Bathanthidium (Bathanthidium s. str.) paco Tran \& Nguyen, sp. nov. from Hoa Binh province is described and illustrated. A nest of the new species is reported from a wooden house. An updated identification key to all known species of the subgenus Bathanthidium s. str. is also provided.
\end{abstract}

\section{Keywords}

Apoidea, Anthidiini, identification key, morphology, taxonomy

\section{Introduction}

Bathanthidium is a small genus of anthidiine bees occurring in eastern Asia (Michener 2007; Ascher and Pickering 2021). It is an uncommonly collected genus with most species known from a small number of specimens and some species lack associated

Copyright Ngat Thi Tran et al. This is an open access article distributed under the terms of the Creative Commons Attribution License (CC BY 4.0), which permits unrestricted use, distribution, and reproduction in any medium, provided the original author and source are credited. 
males. Currently, the genus consists of 12 species belonging to three subgenera: subgenus Bathanthidium s. str. Mavromoustakis, 1953 with three species, Manthidium Pasteels, 1969 with five species and Stenanthidiellum Pasteels, 1968 with four species (Niu et al. 2019). China is considered the distribution center of the genus because almost all its species occur in this country (Niu et al. 2019).

In Vietnam, knowledge concerning the taxonomy of the genus Bathanthidium has been extremely limited as the country has been under sampled for bees. We here report this genus for the first time for the Vietnamese fauna, with a species belonging to subgenus Bathanthidium s. str. described as new to science. A nest site of the new species is also described. In addition, an updated key to all recognized species of the subgenus Bathanthidium s. str. is provided.

\section{Materials and methods}

The materials examined in the present study are deposited in the Hymenopteran collection of the Institute of Ecology and Biological Resources (IEBR), Hanoi, Vietnam. The adult morphological and color characters were examined with a Nikon SMZ745 stereomicroscope. Images were photographed with a Nikon SMZ800N digital stereo microscope, and with ILCE-5000L/WAP2 digital camera attached on that. Photographs were combined with Helicon Focus 7 software to achieve focus stacked images. Finally, all files were processed with Adobe Photoshop CS6.

The morphological terminology used in the description follows Michener (2007).

Measurements of body parts follows Niu et al. (2004): Body length: measured from the base of antennal socket to the apex of metasoma (in dorsal view), head length: measured from the apico-median margin of clypeus to the upper margin of vertex (in frontal view), head width: measured at the widest point of the head across the compound eyes (in frontal view), eye width: the greatest width of eye (in lateral view), genal width: the greatest width of the gena (in lateral view), mesosomal width: measured between the outer rims of the tegulae (in dorsal view).

The abbreviations $S$ and $T(1,2,3 \ldots)$ refer to numbered metasomal sterna and terga, respectively.

\section{Results}

\section{Genus Bathanthidium Mavromoustakis, 1953}

Subgenus Bathanthidium s. str.: Dianthidium (Bathanthidium) Mavromoustakis, 1953: 837. Type species: Dianthidium bifoveolatum Alfken, 1937, by original designation.

Diagnosis. According to Michener (2007) and Niu et al. (2012), the diagnosis of the genus Bathanthidium is as follows: Small to moderate-sized species. Body all black or 
black with yellow markings, with the yellow bands broken on anterior terga; epistomal suture generally straight; medially divided, smooth-floored mesoscuto-mesoscutoscutellar sulcus; preoccipital ridge not carinate; omaular carina absent; pronotal lobe with carina weak or absent; scutellum rounded or medially emarginated, in profile rounded or at least not sharp and not overhanging metanotum; propodeum with a fovea behind spiracle; $2^{\text {nd }} \mathrm{m}$-cu slightly exceeding the apical margin of $2^{\text {nd }}$ submarginal cell; arolia present and large; median S4 of both sexes with pectinate hairs; S5 of the male with pectinate hairs; T6 of the male simple; T7 of the male ranges from simple to trilobed, with the median lobe longest; front coxa of the male normal, without spine.

\section{Bathanthidium (Bathanthidium s. str.) paco Tran \& Nguyen, sp. nov. http://zoobank.org/3769E63C-29F2-4552-8431-620E056400CE Figs 1A-H, 2A-E, 3A-I}

Material examined. Holotype: VIETnAM: + , Hoa Binh, Mai Chau, Pa Co, Hang Kia Pa Co Natural Reserve, 2044'36"N, 10453'42"E, alt. 1340 m, Nest\#VN-HB-2020Bath-01, 24 Jun. 2020, Nguyen LTP, Nguyen CQ, Tran NT \& Mai TV leg., deposited in IEBR. Paratypes: VIETnam: $2 \hat{\jmath}$, same data as holotype, deposited in IEBR.

Diagnosis. Based on the presence of fovea behind propodeal spiracle rounded and delimited by strong carina, the new species belongs to subgenus Bathanthidium s. str.

This species can be distinguished from all other known species of subgenus

Bathanthidium s. str. by the following combination of characters: in the both sexes, mandible widened apically, the lowest tooth slightly rounded; in female, clypeus and mandible in entirely black, paraocular area with thin, yellowish-orange marking extending along the inner margin to the top of the eye, scutellum entirely black, T1 with lateral small, dull orange markings, T2-T5 basally with yellowish-orange bands, T1T2 apically with dull orange bands, the rest of T3-T5 with dull orange to dirty yellow bands, T6 entirely black; in male, T7 of trilobed, median lobe longest and broadest, lateral lobe short, acute and curved inwards, male genitalia large, forked gonostylus with two unequally branches, penis valves with blade shape.

Description. Female (Figs 1, 2). Holotype: Body length $8.5 \mathrm{~mm}$, fore wing length $8.0 \mathrm{~mm}$, head width $2.1 \mathrm{~mm}$, and mesosomal width $3.8 \mathrm{~mm}$.

Head: In frontal view subcircular, approximately 1.2 times as wide as long (Fig. 1A), gena about 0.7 times as wide as eye (Fig. 1G). Mandible widened apically, with 4 teeth, gradually elongate from the first tooth to the fourth tooth, the lowest tooth slightly rounded (Fig. 1B). Clypeus broader than long. Supraclypeal area and clypeus slightly convex.

Mesosoma: Fore wing with two submarginal cells, the first sub-equal in length to second, basal vein nearly straight and meeting $\mathrm{Cu}$ vein at acute angle, $2^{\text {nd }} \mathrm{m}$-cu vein exceeding apical margin of the second submarginal cell, stigma nearly twice as long as broad (Fig. 1E). Outer margin of axilla slightly curved. Scutellum convex, with two foveae at basal margin, each fovea about four times as wide as long and with api- 


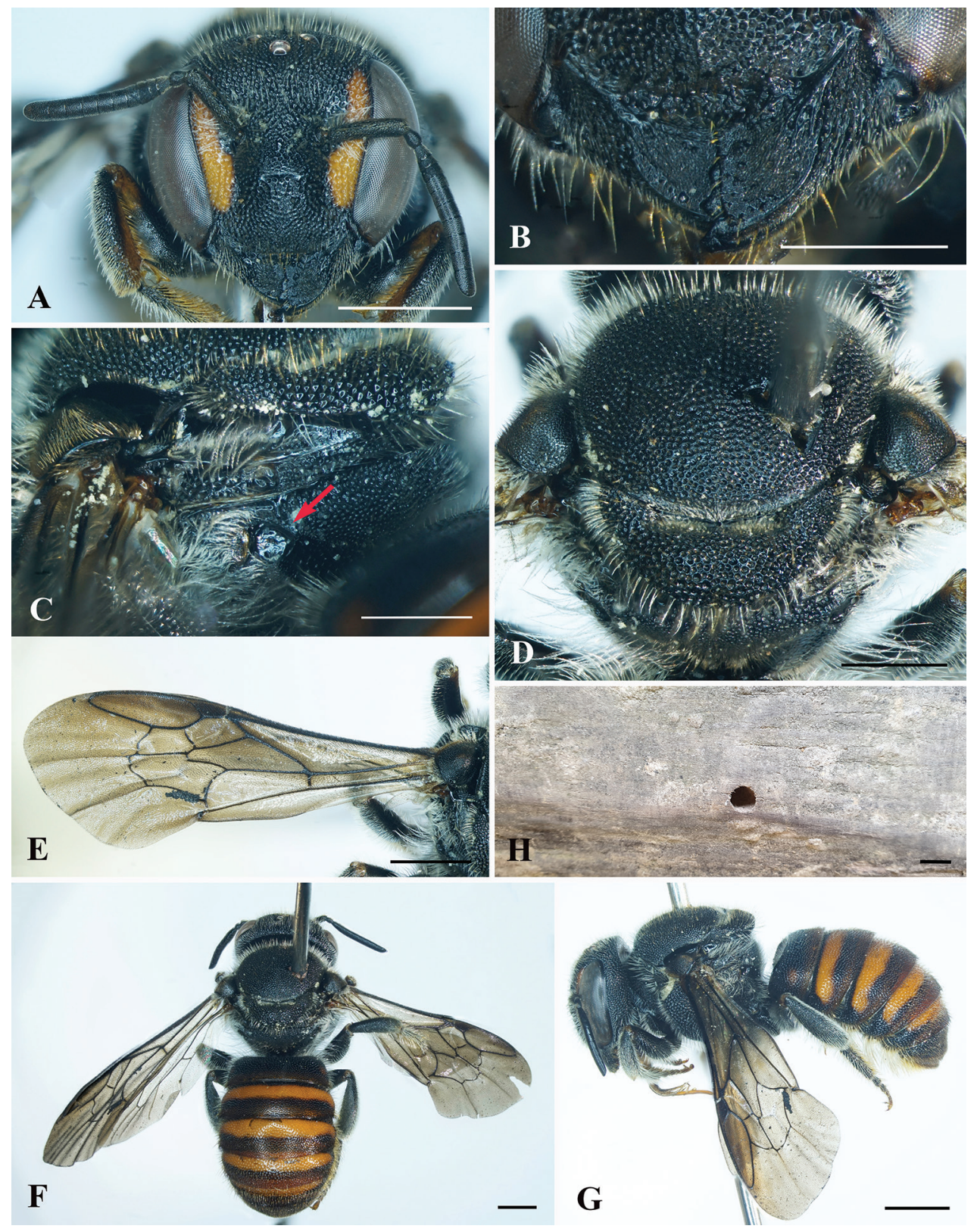

Figure I. A-H Bathanthidium (Bathanthidium s. str.) paco Tran \& Nguyen, sp. nov., holotype, female $\mathbf{A}$ head in frontal view $\mathbf{B}$ mandible in frontal view $\mathbf{C}$ propodeum in lateral view, showing the fovea behind propodeal spiracle $\mathbf{D}$ mesoscutum and scutellum in dorsal view $\mathbf{E}$ fore wing in dorsal view $\mathbf{F}$ habitus in dorsal view $\mathbf{G}$ habitus in lateral view $\mathbf{H}$ nest entrance. Scale bars: $5 \mathrm{~mm}(\mathbf{H}) ; 1 \mathrm{~mm}(\mathbf{A}, \mathbf{C}, \mathbf{E}, \mathbf{F}, \mathbf{G}) ; 0.5 \mathrm{~mm}(\mathbf{B}, \mathbf{D})$,

cal margin slightly emarginated medially (Fig. 1D). Fovea behind propodeal spiracle rounded, delimited by strong carina, basal zone of propodeum distinct laterally, with regular and shiny pits (Fig. 1C). 


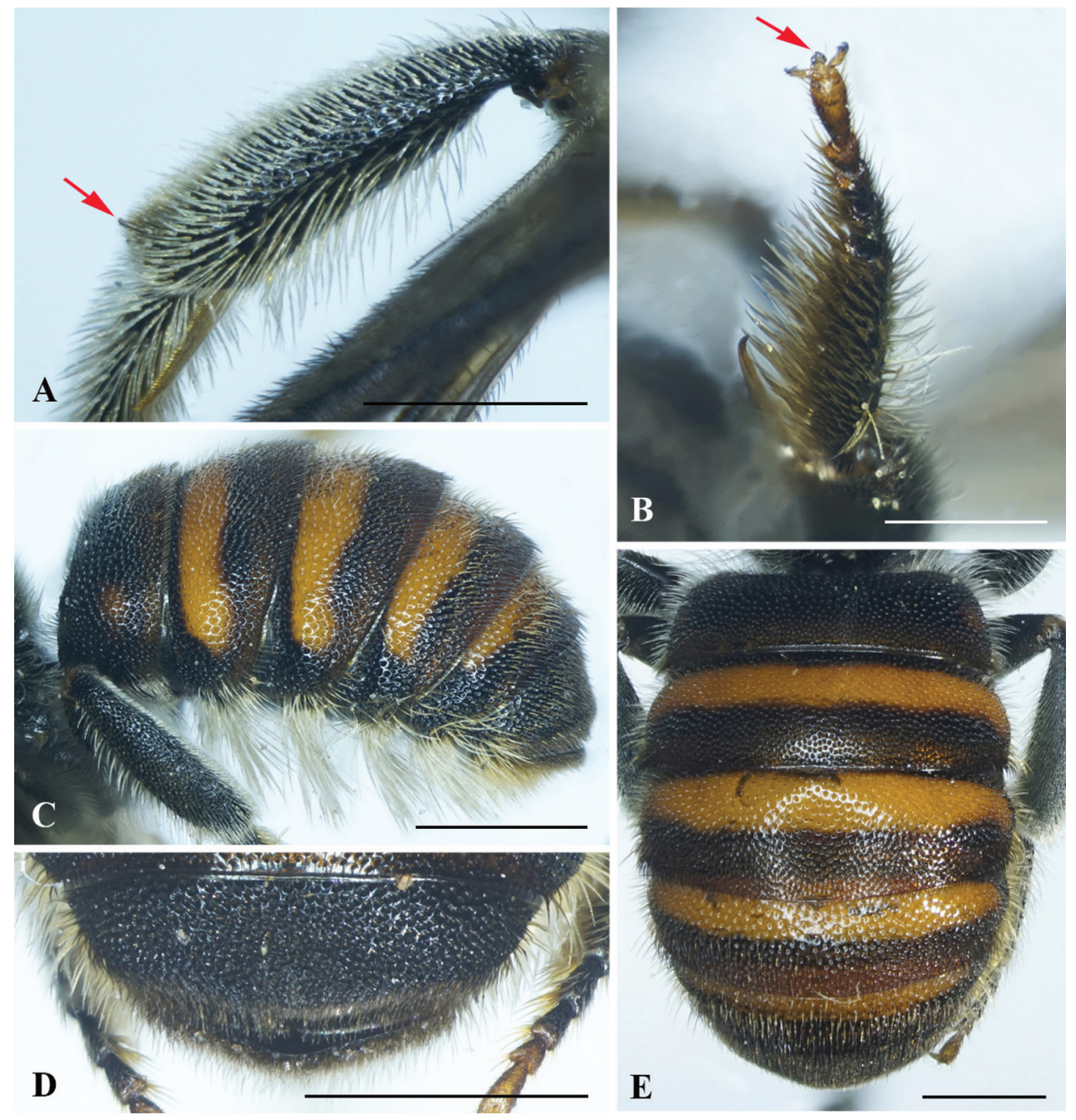

Figure 2. A-E Bathanthidium (Bathanthidium s. str.) paco Tran \& Nguyen, sp. nov., holotype, female A middle tibia in dorso-lateral view, showing the tibial spine B distitarsus of hind leg in frontal view, showing the arolium $\mathbf{C}$ metasoma in lateral view $\mathbf{D}$ T6 in dorsal view $\mathbf{E}$ mesoscutum and scutellum in dorsal view. Scale bars: $1 \mathrm{~mm}(\mathbf{C}, \mathbf{D}, \mathbf{E}) ; 0.5 \mathrm{~mm}(\mathbf{A}, \mathbf{B})$.

Metasoma: T1 with carina on basal margin, T6 with margin round apically (Fig. 2C-D). T6 with large, rough, dense punctures on basal haft and with small, extremely dense punctures on remain part. Fore and middle tibiae in dorso-lateral view with a short spine (Fig. 2A), hind tibia without a spine. Arolia present (Fig. 2B). Pygidial plate absent.

Punctation. Clypeus with large, rough and dense punctures, except the apex with small punctures; frons, vertex, and gena with round, large and dense punctures. Mesoscutum with round and dense punctures, size of the punctures smaller and shallower than that on frons. Scutellum with round and dense punctures, size of punctures uneven. T1-T5 with round, small and sparse punctures on basal half and smaller and denser punctures on remain part. 

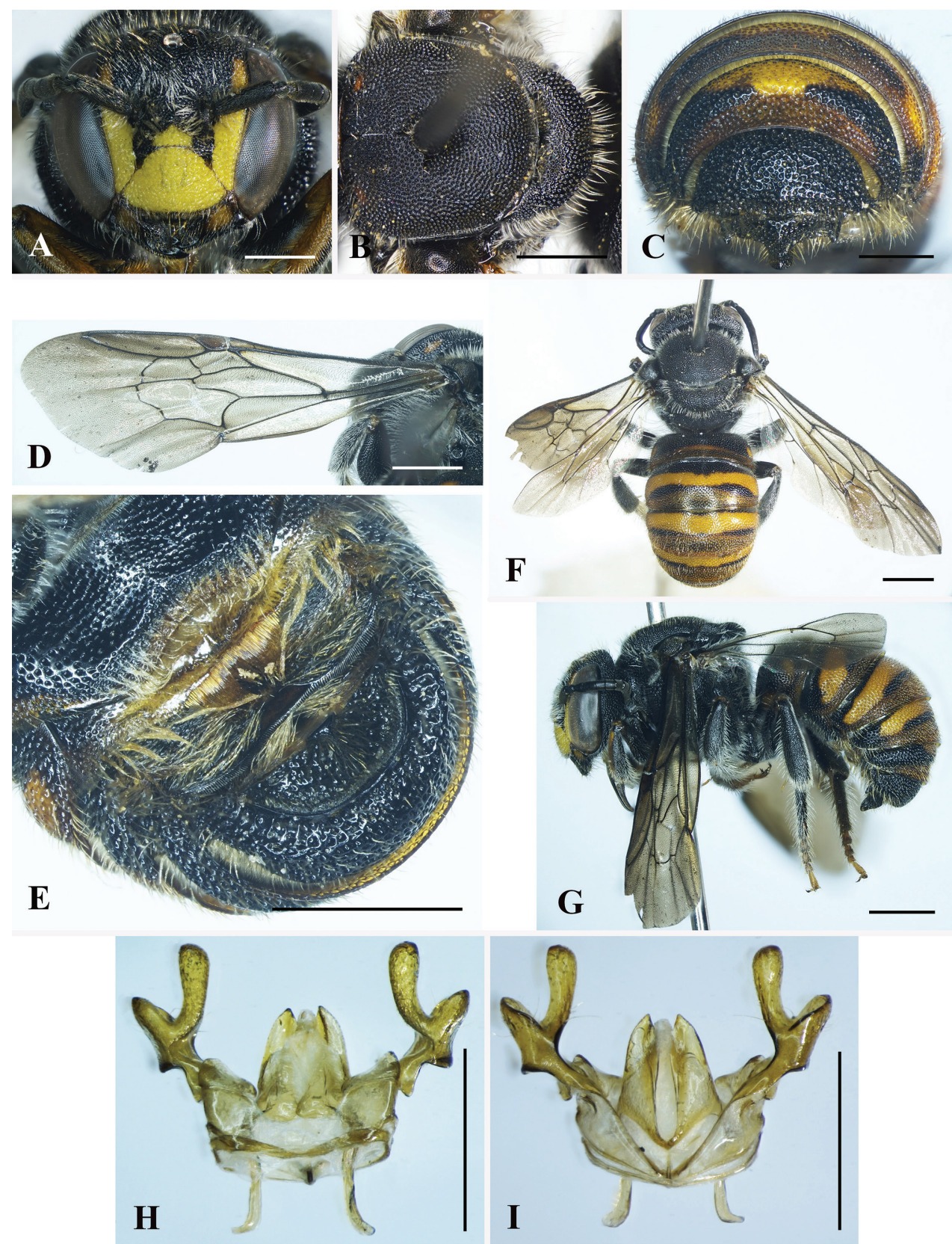

Figure 3. A-I Bathanthidium (Bathanthidium s. str.) paco Tran \& Nguyen, sp. nov., paratype, male A head in frontal view B mesoscutum and scutellum in dorsal view C T4-7 in dorsal view D fore wing in dorsal view $\mathbf{E}$ abdomen in latero-ventral view $\mathbf{F}$ habitus in dorsal view $\mathbf{G}$ habitus in lateral view $\mathbf{H}$ genitalia in dorsal view I genitalia in ventral view. Scale bars: $1 \mathrm{~mm}(\mathbf{A}, \mathbf{B}, \mathbf{D}, \mathbf{E}, \mathbf{F}, \mathbf{G}) ; 0.5 \mathrm{~mm}(\mathbf{C}, \mathbf{H}, \mathbf{I})$. 


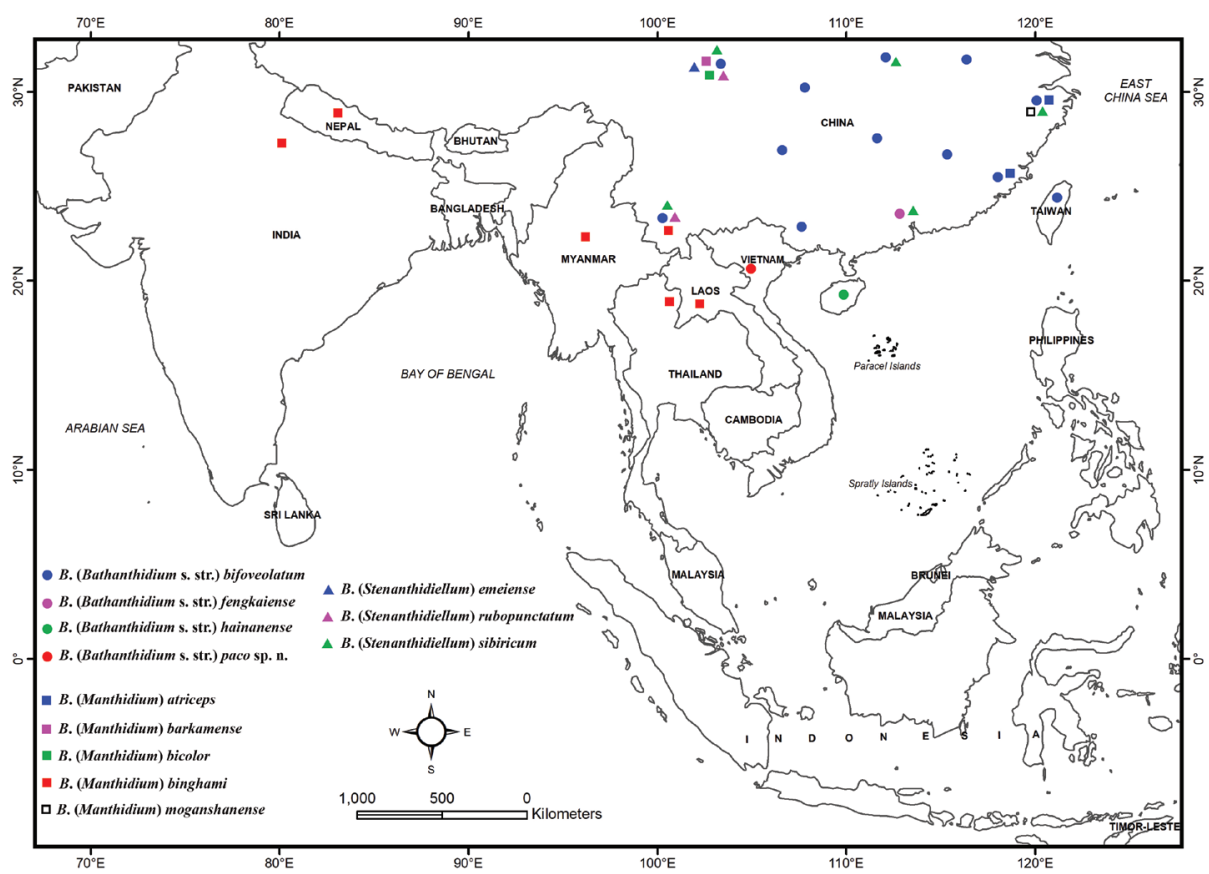

Figure 4. Distribution map of Bathanthidium species in the Indomalayan region.

Pubescence. Clypeus, paraocular area and frons with sparse, short and pale white hairs. Mandible with extremely short, brownish-yellow hairs except for some longer hairs at outer margin. Vertex, mesoscutum, scutellum with short, brownish-yellow hairs. S2-S6 with scopa.

Colour. Paraocular area with thin, yellowish-orange marking extending along the inner margin to the top of the eye (Fig. 1). T1 with lateral small, dull orange markings, T2-T5 basally with yellowish-orange bands, T1-T2 apically with dull orange bands, the rest of T3-T5 with dull orange to dirty yellow bands, T6 entirely black (Fig. 2C-E). Fore and middle femora apically, fore tibia in inside view with dull orange.

Male (Fig. 3). Body length 9-9.2 mm, forewing length 8.5-8.7 mm. Head about 1.2 times as wide as long, gena about 0.7 times as wide as eye.

Most characteristics of the male are similar to those of the female, except for the following:

Metasoma: T7 trilobed, median lobe longest and largest, lateral lobe short, acute and curved inwards (Fig. 3C). Male genitalia large, gonostylus forked with two unequal branches, penis valve with blade shape (Fig. 3H-I).

Colour. Clypeus yellow, supraclypeal area with small yellow marking, paraocular area with thin, long and yellow to yellowish-orange marking extending along the inner margin to the top of the eye (Fig. 3A). Mandible basally with dull yellow marking. Gena with yellowish-orange markings near the apical margin of the eye, mesoscutum latero-anteriorly with small yellowish-orange spots (sometimes 
absent), scutellum entirely black (Fig. 3B). Inner surface of fore femur apically, fore tibia, fore basitarsus, middle femur apically, and middle tibia with dull orange markings. T1 with lateral small, light yellowish-orange markings; T2 medially with light yellowish-orange bands, T3-T5 basally with light yellowish-orange bands; T1, T2, T5 apically with dirty yellow bands; most of the rest of T3 and T4 with dirty yellow bands; T6 and T7 entirely black (Fig. 3C, F-G). Fore and middle femora apically, fore tibia in inside view with dull orange.

Pubescence. The median part of S3 orange, apical margin of S2-S3 with pale white to dull orange feather combs, $\mathrm{S} 4$ shiny on basal half and with short, dense, pale white hairs on remain part and simple hair comb in apical margin, $S 5$ shiny on basal half and short, sparser, pale yellow hairs on remaining part with black, serrated papillae at apical margin (Fig. 3E).

Remarks. This species is most similar to B. (Bathanthidium) bifoveolatum (Alfken, 1937), but can be easily distinguished from the later by the mandible with the lowest tooth slightly rounded in both sexes (mandible with the lowest tooth acute in both sexes of $B$. bifoveolatum); clypeus entirely black in female (clypeus laterally with yellow markings in female of $B$. bifoveolatum); mandible basally with dull yellow marking in male (mandible with yellow marking extending from base to nearly top in male of B. bifoveolatum); mesoscutum latero-anteriorly with small faint yellowish-orange spots or absent, scutellum, pronotal lobe black in both sexes (mesoscutum anteriorly and scutellum apically with thin and long yellow marking interrupted medially; pronotal lobe with yellow marking basally in both sexes of $B$. bifoveolatum); T2 with yellowish-orange entirely bands, not interrupted medially in both sexes (T2 laterally with yellow markings in both sexes of B. bifoveolatum).

Nest biology. A nest was discovered in a wooden plank in the door of a house, the entrance hole of the nest with a diameter of about $4 \mathrm{~mm}$ (Fig. 1H). A female specimen was observed and collected when flying out from the nest. Male specimens were collected in the garden behind the wooden house.

Distribution. Northern Vietnam (Hoa Binh province).

Etymology. The specific name refers to the type locality, $\mathrm{Pa}$ Co commune in Hoa Binh province, it is treated as a noun in apposition.

\section{An updated key to the species of the subgenus Bathanthidium s. str.}

(Based on Niu et al. 2019, males of B. fengkaiense Niu \& Zhu, 2019 and B. hainanense Niu, Wu \& Zhu, 2012 are unknown)

$1 \quad$ Flagellum 10-segmented, female

- $\quad$ Flagellum 11-segmented, male 5

2 Paraocular area with thin and long yellow or yellowish-orange marking extending along the inner margin to the top of the eye..................................... 3

- Paraocular area near ventral extreme with a small sub-triangle or sub-rectangle dull yellow marking 
3 Mandible with the lowest tooth acute (see fig. 34 in Niu et. al 2012). Clypeus laterally with yellow markings (see fig. 31 in Niu et al. 2012), mesoscutum anteriorly and scutellum apically with thin yellow marking interrupted medially (see fig. 29 in Niu et al. 2012)

B. (Bathanthidium s. str.) bifoveolatum (Alfken, 1937)

- $\quad$ Mandible with the lowest tooth slightly rounded (Fig. 1B). Clypeus, mesoscutum and scutellum entirely black (Fig. 1A, D)

B. (Bathanthidium s. str.) paco, sp. nov. T2 entirely black, T3-T5 with yellow bands, the band on T3 obviously interrupted medially (see fig. $2 \mathrm{~d}$ in Niu et al. 2019); mandible with the lowest tooth acute, distance between each two of the three basal teeth short and concave (see fig. 1e in Niu et al. 2019)

B. (Bathanthidium s. str.) fengkaiense Niu \& Zhu, 2019

- $\quad$ T2 with a pair of small, stripe-like yellow markings medially, T3-T5 with broader yellow bands, not interrupted medially (see fig. 12 in Niu et al. 2012); mandible with the lowest tooth slightly rounded, distance between each two of the three basal teeth longer and lesser concave (see fig. 5 in Niu et al. 2012)

B. (Bathanthidium s. str.) hainanense Niu, Wu \& Zhu, 2012

Mandible with yellow marking extending from base to nearly top (see fig. 39 in Niu et al. 2012). Mesoscutum anteriorly and scutellum apically with thin yellow marking interrupted medially (see fig. 36 in Niu et al. 2012)

B. (Bathanthidium s. str.) bifoveolatum (Alfken, 1937)

- Mandible basally with dull yellow marking (Fig. 3A). Mesoscutum latero-anteriorly with small, yellowish-orange markings or absent, scutellum entirely black (Fig. 3B)

B. (Bathanthidium s. str.) paco, sp. nov.

\section{Discussion}

Bathanthidium has a primarily Indomalayan distribution with almost all the described species (except B. malaisei from South Korea, and depending on whether or not one considers $B$. emeiense and B. bicolor to occur in Indomalaya) occuring in this biogeographic realm, the majority having been reported from southern China. The discovery of $B$. paco in northern Vietnam is both consistent with this pattern and extends the range of Bathanthidium.

Very little is known of the biology of Bathanthidium. The only description of a nest of any Bathanthidium is that of Romankova (1988) who observed B. (Stenanthidiellum) malaisei (Popov) (as Lasianthidium malaisei (Popov)) constructing linear series of resin cells in preexisting cavities in wood. This is consistent with the observation that anthidiines with three of four mandibular teeth (like Bathanthidium) typically construct their nests with resin (Michener 2007: 492). Michener (2007: 512) also noted that the slender body-form of members of Bathanthidium s. str. and Stenanthidiellum 
suggested that, like other similarly shaped megachilids, they probably nest in narrow, preexisting cavities in wood. Our discovery of a female of B. paco emerging from a narrow hole in a wood plank is consistent with this suggestion and is the first observation of a probable nest site of any Bathanthidium s. str. species.

\section{Acknowledgements}

The authors would like to thank the subject editor, Jack Neff, and an anonymous reviewer for their valuable comments to improve the draft quality. We are also sincerely thank the Director (Mr. Luong Thanh Nguyen) and staffs (Mr. Khanh Tien Nguyen and Mr. Cong Van Bui) of Hang Kia - Pa Co Natural Reserve for providing support and permission. The present study was supported by the Vietnam Academy of Science and Technology under two grants (ĐLTE00.04/22-23 and QTBG01.01/21-22).

\section{References}

Alfken JD (1937) About two new Apidae from China. Entomology and Phytopathology Hangchow 20: 404-406.

Ascher SJ, Pickering J (2021) Discover Life bee species guide and world checklist (Hymenoptera: Apoidea: Anthophila). http://www.discoverlife.org/mp/20q?guide=Apoidea_species [Accessed 19 August 2021]

Mavromoustakis GA (1953) New and little-known bees of the subfamily Anthidiinae (Apoidea), Part VI. Annals and Magazine of Natural History 12(6): 834-840. https://doi. org/10.1080/00222935308654492

Michener CD (2007) The Bees of the World ( $2^{\text {nd }}$ edn). The Johns Hopkins University Press, Baltimore, 953 pp. [920 pls]

Niu ZQ, Wu YR, Zhu CD (2012) A new species of Bathanthidium Mavromoustakis (Hymenoptera: Megachilidae: Anthidiini) from China, with a key to the species. Zootaxa 3218: 59-68. http://doi.org/10.11646/zootaxa.3218.1.6

Niu ZQ, Ascher JS, Griswold T, Zhu CD (2019) Revision of the bee genus Bathanthidium Mavromoustakis (Hymenoptera: Apoidea: Megachilidae: Anthidiini) with description of a new species from China. Zootaxa 4657(1): 097-116. http://doi.org/10.11646/zootaxa.4657.1.3

Niu ZQ, Wu YR, Huang DW (2004) A taxonomic study on the subgenus Seladonia (Hymenoptera, Halictidae, Halictus) in China with description of one new species. Zoological Studies 43(4): 647-670.

Pasteels JJ (1968) Statut, affinités et origines des Anthidiinae parasites (Hymenoptera, Apoidea, Megachilidae). Naturaliste Canadien 9: 1055-1063.

Pasteels JJ (1969) La systématique générique et subgénérique des Anthidiinae (Hymenoptera, Apoidea, Megachilidae) de l'ancien monde. Mémoires de la Société Royale d'Entomologie de Belgique 31: 1-148.

Romankova TG (1988) A new far-eastern bee of the tribe Anthidiini. Vestnik Zoologii 4: 25-30. 